\title{
Keanekaragaman Capung (Odonata) Di Tepi Sungai Kali Desa Kali Kabupaten Minahasa Sulawesi Utara
}

\author{
Juniati Lino ${ }^{{ }^{*}}$, Roni Koneria*, Regina Rosita Butarbutara* \\ aJurusan Biologi, FMIPA, Unsrat, Manado
}

KATA KUNCI

Capung

Libellulidae

Neurothemis ramburii

Sungai Kali

Sulawesi Utara

\begin{abstract}
A B S T R A K
Capung merupakan komponen keanekaragaman hayati yang memiliki peran sebagai bioindikator pencemaran lingkungan. Penelitian ini bertujuan untuk mengidentifikasi spesies dan menganalisis keanekaragaman capung di Sungai Kali Desa Kali, Kabupaten Minahasa, Sulawesi Utara. Pengambilan sampel dilakukan dengan mengunakan metode purposive random sampiling. Penelitian ini dilaksanakan pada tepi sungai kali yang terletak pada tiga tipe habitat yaitu di tepi sungai hutan sekunder, tepi sungai perkebunan dan tepi sungai permukiman. Masing-masing habitat dibuat tiga garis transek dengan panjang 300 Meter. Komposisi capung yang diperoleh terdiri dari 6 famili, 19 spesies dan 1.785 individu. Famili yang paling banyak ditemukan jumlah spesiesnya adalah Libellulidae. Spesies yang memiliki kelimpahan yang tertinggi Neurothemis ramburii dan Ortetrum pruinosum. Indeks kekayaan spesies di Sungai Desa Kali di kategorikan rendah, indeks keanekargaman di kategorikan sedang dan indeks kemerataan spesies tergolong dalam ketegori tinggi
\end{abstract}

K E Y W O R D S

Dragonfly

Libellulidae

Neurothemis ramburii

Kali River

North Sulawesi
TERSEDIA ONLINE

01 Agustus 2019

1. Pendahuluan

Capung termasuk dalam kelompok filum Arthropoda dan ordo Odonata. Odonata dalam bahasa Yunani artinya rahang bergigi dimana pada ujung labium (bibir bawah) terdapat tonjolantonjolan tajam atau spina yang menyerupai gigi (Borror et al., 1996). Capung dikelompokkan dalam dua sub ordo yaitu Zygoptera (2.739 spesies dan 19 famili) dan sub ordo Anisoptera (2.941 spesies dan 12 famili) serta sekitar 1.000 hingga 1.500 spesies belum dideskripsikan (Mapi-ot et al., 2013). Perbedaan dari kedua jenis capung ini adalah bentuk dan ukuran tubuh, dimana capung biasa (Anisoptera) lebih besar dari pada capung jarum (Zygoptera) dan capung biasa lebih cepat terbangnya dari pada capung jarum. Biasanya capung dapat dijumpai di tempat-tempat yang dekat dengan sumber air dan hidup sebagai serangga (entomofagus) yaitu serangga yang memakan jenis serangga lain yang berukuran lebih kecil, tetapi juga

*Corresponding author: Jurusan Biologi FMIPA UNSRAT, Jl. Kampus Unsrat, Manado, Indonesia 95115; Email address: juniatilino@gmail.com

Published by FMIPA UNSRAT (2019) 
kadang-kadang memakan daun tumbuh-tumbuhan (Amir dan Kahono, 2003).

Jumlah spesies capung di dunia sekitar 6.580 spesies (Kalkman, 2013). Serangga ini tersebar di seluruh dunia dengan jumlah yang banyak dan melimpah terutama di daerah tropis seperti Indonesia. Hal ini disebabkan karena Indonesia berada pada kawasan tropis yang memiliki bermacam-macamhabitatsehinggakeanekaragaman capung melimpah (Borror et al., 1996). Jumlah spesies capung di Indonesia terdapat sekitar 750 jenis, beberapa jenis di antaranya endemik di Sulawesi, misalnya Gynacantha Penelope Ris. (Anisoptera: Aeshnidae) (Susanti, 1998). Spesies capung yang ditemukan di Sulawesi sebanyak 143 spesies (Tol, 2000), yang terdiri dari 50 spesies Zygoptera dan 93 spesies Anisoptera (Tol, 1987).

Capung merupakan salah satu komponen keanekaragaman hayati yang memegang peranan penting dalam jaringan makanan (Strong et al., 1984). Capung memiliki peranan dalam ekosistem sebagai agen pengendali hayati. Capung sebagai agen pengendali hayati yaitu sebagai predator dan dapat mengurangi $p$ opulasi hama pada tanaman pangan. Salah satu peran capung adalah sebagai predator hama, bahkan capung jarum (Subordo: Zygoptera) ikut berperan sebagai musuh alami yang dapat mengurangi populasi hama tanaman pangan (Ariwibowo, 1991). Hal ini menunjukkan posisi penting keberadaan capung dalam keseimbangan ekologi. Capung juga dapat dijadikan sebagai indikator pencemaran lingkungan (bioindikator).

Sungai Desa Kali merupakan salah satu habitat capung. Sungai tersebut terletak di Desa Kali, Kecamatan Pineleng, Kabupaten Minahasa, Sulawesi Utara. Sungai tersebut terdapat air terjun Kali yang merupakan salah satu objek wisata yang sering di kunjungi oleh masyarakat sekitar. Penelitian tentang keanekargaman capung di tepi Sungai Desa Kali belum pernah dilakukan dan belum ada data tentang keanekaragaman capung di sungai tersebut. Penelitian ini bertujuan untuk mengidentifikasi spesies dan menganalisis keanekaragaman capung di Sungai Kali Desa Kali, Kabupaten Minahasa, Sulawesi Utara.

\section{Bahan dan Metode}

Penelitian dilaksanakan pada bulan Januari Februari 2019. Lokasi penelitian di tepi Sungai Kali Desa Kali Kecamatan Pineleng Kabupaten Minahasa Sulawesi Utara. Alat dan bahan yang digunakan adalah alkohol 70\% yang dipakai untuk membunuh capung, kertas minyak/kertas papilot (dibentuk amplop), jaring serangga (sweepnet) untuk manangkap capung,buku identifikasi capung, alat tulis, dan kotak koleksi. Alat yang dipakai mengukur faktor lingkungan ialah termohigro, GPS (Global Positioning System) untuk mencatat koordinat dan ketiggian tempat dan untuk dokumentasi digunakan kamera.

Metode yang digunakan yaitu purposive random sampling (Magurran, 1998) Lokasi dibagi tiga dibagi menjadi tiga habitat yaitu: tepi sungai hutan sekunder, tepi sungai perkebunan dan tepi sungai permukiman. pada masing-masing stasiun dibuat tiga garis transek dengan panjang 300 meter dengan jarak antar stasiun 50 meter. Proses indetifikasi. Proses identifikasi berdasarkan ciri morfologi eksternal menggunakan buku Theischinger (2009); Orr (2003); Kalkman (2013); Watson dan Farrel (1991); Miller (1995); Wilson (1995).

\section{Hasil dan Pembahasan}

Capung yang ditemukan dalam penelitian ini dua sub ordo, enam famili, 13 genus, 19 spesies dan 1.785 individu (Tabel 1). Sub ordo Anisoptera yang ditemukan hanya satu famili yaitu Libellulidae dengan delapan spesies sedangkan Zygoptera terdiri dari lima famili yaitu Coenagrionidae tujuh spesies dan Argiolestidae, Calopterygidae, Lestisdae, Platycnemididae masing-masing terdiri dari satu spesies (Tabel 1). Kelimpahan famili capung yang paling banyak adalah Libellulidae dengan jumlah sebanyak 55,01\% sedangkan kelimpahan famili yang paling sedikit ditemukan adala Argiolestidae 0,06\% (Gambar 1).

Tabel 1. Keanekaragaman capung (Odonata) tiga habitat di tepi Sungai Kali

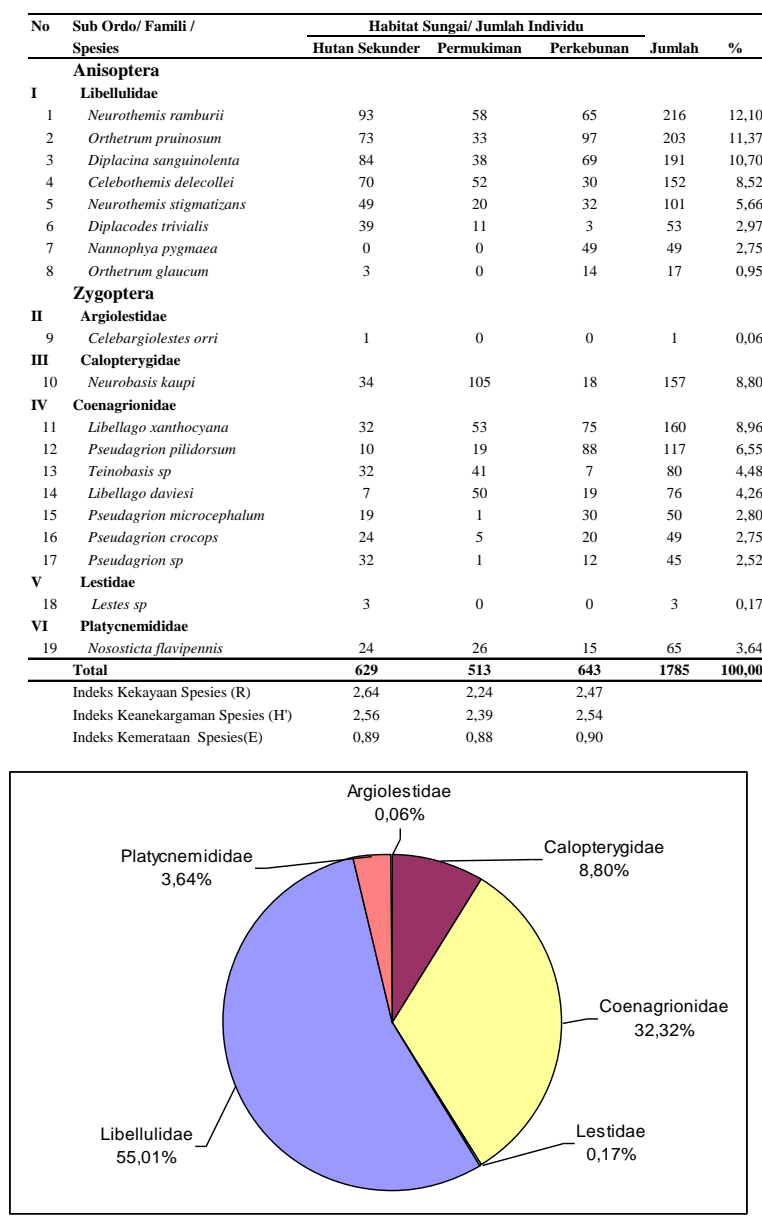

Gambar 1. Kelimpahan famili capung di tepi Sungai Kali Desa Kali, Kabupaten Minahasa, Sulawesi Utara 
Hasil penelitian capung ini ditemukan 13 genus dari enam famili terdiri dari Libellulidae terdiri dari enam genus, Coenagrionidae tiga genus, Calopterygidae satu genus, Argiolestidae satu genus, Lestidae satu genus, dan Platycnemididae satu genus. Genus Pseudagrion merupakan genus dengan jumlah spesies terbanyak yaitu empat spesies, kemudian diikuti oleh genus Libellago (dua spesies). Spesies capung yang paling banyak jumlah individunya adalah Neurothemis ramburii sebanyak 216 individu, kemudian diikuti oleh Orthetrum pruinosum 203 individu Spesies dengan jumlah individunya yang paling sedikit adalah Celebargiolestes orr sebanyak satu individu atau 0,06\% kemudian Lestes sp sebanyak tiga individu $(0,17 \%)$ (Tabel 1). Berdasarkan tipe habitat ditemukan bahwa kelimpahan individu capung tertinggi terdapat pada tepi sungai di lahan perkebunan (643 individu atau 36,02\%) kemudian di hutan sekunder sebanyak 629 individu (35,24\%) (Tabel 1).

Analisis keanekaragaman capung yang dianalisis meliputi indeks kekayaan spesies (R), indeks keanekaragaman spesies $\left(\mathrm{H}^{\prime}\right)$ dan indeks kemerataan spesies (E). Indeks kekayaan spesies (R) capung yang tertinggi ditemukan pada hutan sekunder, kemudian diikuti oleh sungai pada habitat perkebunan. Indeks kekayaan spesies terendah terdapat pada sungai di kawasan permukiman. Indeks kekayaan spesies yang ditemukan di Sungai Kali Desa Kali tergolong rendah Indeks keanekaragaman spesies $\left(\mathrm{H}^{\prime}\right)$ capung tertinggi ditemukan pada hutan sekunder selanjutnya di perkebunan dan indeks keanekaragaman spesies terendah terdapat pada sungai di kawasan permukiman. Keanekaragam capung di Sungai Kali, Desa Kali tergolong keanekaragaman sedang. Indeks kemerataan spesies (E) capung tertinggi ditemukan pada perkebunan dan diikuti oleh habitat hutan sekunder yang mempunyai nilai tidak jauh berbeda dengan hutan sekunder. Indeks kemerataan spesies terendah terdapat pada sungai di kawasan permukiman. Indeks kemerataan spesies capung pada sungai yang terletak pada lahan perkebunan dan hutan sekunder dikategorikan tinggi, sedangkan pada permukiman tergolong rendah.

Perbedaan keanekaragaman capung pada tiga tipe habitat disebabkan karena kondisi habitat dan kompleksitas struktur vegetasi. Hutan sekunder memiliki struktur vegetasi yang lebih rapat yang tersusun berbagai famili tumbuhan seperti Tectona grandis (jati), Pometia pinnata (matoa), Ficus benjamina (beringin), Terminalia catappa (ketapang), Swietenia mahagoni (mahoni), Bambusa sp (bambu), Arenga pinnata (pohon aren), Pandanus sp (pandan), Calathea lutea, Chromolaena odorata (kirinyuh) dan Piper aduncum (sirih hutan) dan dibandingkan dengan lahan pertanian memiliki stuktur vegetasi yang kurang rapat atau sedikit terbuka yang hanya terdiri dari beberapa tanaman pertanian seperti Musa paradica (pisang), Cocos nucifera (kelapa), Carica papaya (pepaya), Caladium Sp (keladi), Arthocarpus heterophyllus (nangka) dan berbagai macam spesies Poacea (rumputrumputan). Habitat permukiman memiliki struktur vegetasi yang lebih terbuka yang terdiri dari beberapa tumbuhan seperti Pinnisettum purpureum (rumput gajah), Bambusa sp (bambu) Cyperus sp (teki) dan Poacea (Rumput-rumputan).

Vegetasi yang terdapat di tepi sungai sangat berpengaruh terhadap perilaku capung dewasa seperti berjemur mencari makan, istrahat dan berlindung atau bertuduh (Silva et al., 2010). Capung juga menggunakan vegetasi akuatik untuk tempat meletakkan telur dan memasukkan telur kedalam tumbuhan atau pohon yang terendam (Harabis et al., 2017). Telur capung yang telah menetas akan menjadi nympa dan nympa mengunakan vegetasi air untuk bertengger, bersembunyi dari pemangsa dan untuk hinggap menunggu mangsanya (Buchwald, 1992).

Tingginya nilai indeks kekayaan dan indeks keanekaragaman spesies capung pada sungai yang terdapat pada hutan sekunder karena masih rapatnya vegetasi dibandingkan dengan lahan perkebunan dan kawasan permukiman. Menurut Dolny et al. (2011) pada habitat hutan yang masih sangat rapat dan belum adanya gangguan serta alih fungsi hutan menyebabkan tingginya keanekaragaman dari capung. Kualitas perairan yang masih baik pada daerah berhutan karena belum adanya aktivitas manusia sangat menentukan tingginya kekayaan dan keanekaragaman capung yang ditemukan. Struktur habitat, seperti struktur vegetasi, sangat penting untuk semua spesies capung (Niba and Samways, 2006)

Nilai indeks kemerataan spesies capung tertinggi ditemukan pada kawasan perkebunan dan nilainya tidak jauh berbeda dengan kawasan hutan sekunder dan kawasan permukiman .Indeks kemerataan yang tinggi untuk tiap habitat menunjukkan tidak ada spesies capung yang dominan. Semakin kecil nilai indeks kemerataan spesies, maka penyebaran spesies tidak merata dan terjadi dominasi oleh spesies capung tertentu (Magurran, 1988). Hal ini menunjukkan bahwa pada hutan sekunder dan kawasan permukiman tidak ada spesies capung yang mendominasi. Menurut Rahayuningsih et al. (2012) tingginya indeks kemerataan spesies di suatu daerah menunjukkan bahwa habitat di daerah tersebut lebih stabil dibandingkan habitat dengan kemerataan spesies yang rendah.

\section{Kesimpulan}

Jumlah spesies capung yang ditemukan pada ketiga habitat di tepi Sungai Desa kali Kecamatan Pineleng Kabupaten Minahasa Sulawesi Utara 6 famili 19 spesies dan 1.785 individu. Famili yang paling banyak ditemukan jumlah individunya adalah Libellulidae sedangkan yang paling sedikit adalah Argiolestidae dan Lestesdae. Neurothemis ramburii 
dan Orthetrum pruinosum paling banyak jumlah individunya sedangkan yang paling sedikit Celebargiolestes orr dan Lestes sp. Kelimpahan spesies tertinggi di habitat perkebunan sedangkan yang terendah di habitat permukiman, indeks kekayaan spesies dan indeks keanekaragaman spesies capung pada habitat hutan sekunder lebih tinggi dibandingkan dengan lahan perkebunan dan tepi sungai di permukiman. Kemerataan spesies tertinggi didapatkan di habitat perkebunan sedangkan yang rendah pada habitat permukiman. Indeks kekayaan spesies dan indeks keanekargaman spesies yang didapatkan di lokasi penelitian dikategorikan sedang, sedangkan kemerataan spesies tergolong dalam ketegori tinggi.

\section{Daftar Pustaka}

Amir dan Kahono, 2003. Serangga Taman Nasional Gunung Halimun Jawa Bagian Barat. Biodiversity Conservation Project. Jawa Barat.

Ariwibowo, D. 1991. Kajian Biologik Capung Jarum, Agriocnemis pymaea (Rambur) Selys sebagai Musuh Alami Wereng Coklat, Nilaparvata lugens [Tesis]. Institut Pertanian"STIPER". Yogyakarta.

Buchwald, R. 1992. Vegetation and Dragonfly Fauna Characteristics and Examples of Biocenological Field Studies. Vegetatio 101:99-107

Borror, D.J., C.A. Triplehorn, dan N.F. Johnson, 1996. Pengenalan Pelajaran Serangga Edisi Keenam. Gadja Mada University Press. Yog yakarta.

Dolny A., D. Barta., Lhota., Rusdiato, and P. Drozd. 2011. Dragoflies (Odonata) in the Bornean Rain Forest as Indicator of Changes in Biodiversity Resulting from Forest Modification and Destruction. Tropical Zoology. 24:63-86.

Harabis.F and A. Dolny. Ecological Factors Determining the Density Distribution of Central European Dragonflies (Odonata). Jurnal Entomol. 107: 571-577.

Kalkman, V., and A.G. Orr. 2013. Field Guide to the Damselflies of New Guinea. Scholma Druk BV. Bedum Netherlands.

Niba, AS., and M.J. Samways. 2006. Remarkable Elevation Tolerance in an African Odonata Larval Assemblage. Odonatologica. 35 (3): 265-280.

Magurran AE. 1998. Ecological Diversity and its Measurements. Croom Helm Limited. London.

Miller, PL. 1995. Visually Controlled Head Movements in Perched Anisopteran Dragonflies. Odonatologi. 3: 301-310.

Mapi-ot, EF., A.U.Taotao., O.M.Nurieza., J.T.Reagan., and R.J.T. Villanueva. 2013. Spesies Diversity of Adult Odonata in Selected Areas from Misamis Occidental Province, Philippines. AACL Bioflux. 6(4):421-432.

Orr, A.G. 2003. A Guide to Dragonflies of their Identification and Biology. Natural History Publication (Borneo). Kinabalu

Rahayuningsih.M., R. Oktafiana dan B. Priyono. 2012. Keanekaragaman Spesies Kupu-Kupu Superfamili Papilionidae di Dukuh Banyuwindu Dara Limbangan Kecamatan Limbangan Kabupaten Kendal. Jurnal MIPA 35(1): 2.
Silva, D. P., P. De Marco.,and D.C. Resende. 2010. Adult Odonste Abundance and Community Assemblage Measures as Indicators of Stream Ecological Integrity: A Case Study. Ecological indicator. 10: 744-752.

Strong, D.R., J.H. Lawton, and R. Southwood, 1984. Insects on Plants. Harvard University Press. Boston.

Susanti, S. 1998. Seri Panduan Lapangan Mengenal Capung. Puslitbang Biologi- LIPI. Bogor

Theischinger, G. 2009. Identification Guide to the Australia Odonata. Depertemen of Environtment, Climate Change and Water NS. Sydney.

Tol JV. 1987. The Odonata of Sulawesi (Celebes), Indonesia an Introduction. Odonatol. 3: 147-155.

Tol JV. 2000. The Odonata of Sulawesi and Adjacent Island, the Genus Protisticta Selys (Platystictidae). Tijdschr. Ent. 143: 221-266.

Watson, J. A. L., Farell and AFO. 1991. Odonata in (dragonflies and damselfly) Division of entomologi CSIRO. Melbourne University Press. Australia.

Wilson, K.D.P. 1995. Hong Kong Dragonflies. Urban Council. Hongkong 